Annals of International Medical and Dental Research

E-ISSN: 2395-2822 | P-ISSN: 2395-2814

Vol-8, Issue-2 | March-April 2022

DOI: 10.53339/aimdr.2022.8.2.20

Page no- 145-156 | Section- Research Article (Orthopedics)

\title{
Comparative Study of Arthroscopic Anterior Cruciate Ligament Reconstruction by Quadrupled Semitendinosus-Gracilis and Tripled Semitendinosus Auto Graft
}

\author{
Maksud Ahmmad1, Md. Samiul Islam²*, Md. Ehteshamul Choudhury ${ }^{3}$, Mohd. Sayedul Islam, \\ Md. Asaduzzaman ${ }^{5}$, Khan Ashabul Haque
}

1Combined Military Hosital, Department of Orthopedics, Savar, Dhaka., Bangladesh.

ORCID: 0000-0002-6943-4996

2National Institute of traumatology and Orthopedic Rehabilitation, Dhaka. Bangladesh.

ORCID: 0000-0002-8293-6595

${ }^{3}$ Medical Officer, Department of Orthopedics Bangabandhu Sheikh Mujib Medical University (BSMMU), Shahbag, Dhaka, Bangladesh. ORCID: 0000-0003-1026-7764

${ }^{4}$ Associate Professor, 250 Bedded General Hospital, Kushtia, Bangladesh.

ORCID: 0000-0001-5348-7113

${ }^{5}$ National Institute of Traumatology \& orthopedic rehabilitation, (NITOR) Dhaka, Bangladesh.

ORCID: 0000-0002-5636-3949

${ }^{6}$ National Institute of Traumatology \& orthopedic rehabilitation, (NITOR) Dhaka, Bangladesh.

ORCID: 0000-0002-9015-7102

*Corresponding author

Received: 18 November 2021

Revised: 21 January 2022

Accepted: 03 February 2022

Published: 18 February 2022

\begin{abstract}
Background: The anterior cruciate ligament (ACL) is the most frequently disrupted ligament of the knee. Arthroscopic ACL reconstruction is one of the most common orthopaedic procedures now-a-days and has become the gold standard method of treatment in complete ACL tear. Though the choice of graft for ACL reconstruction and the methods of its fixation are matters of debate, hamstring tendon is considered as the favorable graft. Common options for the choice of graft are quadrupled semitendinosus-gracilis and tripled semitendinosus auto graft. Aim of our study is to compare the outcome of arthroscopic ACL reconstruction by quadrupled semitendinosus-gracilis and tripled semitendinosus auto graft. Material \& Methods: In this prospective interventional study purposive sampling was done. Sixty patients with complete ACL tear were included in this study from May 2017 to August 2019 at NITOR, strictly considering the inclusion and exclusion criteria. Thirty of them treated with quadrupled semitendinosus-gracilis (group 1) and thirty with tripled semitendinosus (group 2) auto graft. Evaluation by Lysholm knee score was done before and after surgery. Final outcome was evaluated at 24th week postoperatively. Results: Preoperative Lysholm Knee Score was almost similar in group $1(63.2 \pm 2.1)$ and in group $2(63.1 \pm 2.5)$. This difference was not statistically significant $(\mathrm{p}=0.582)$. Postoperative Lysholm Knee Score at 24th week was slightly higher in group $1(95.0 \pm 2.0)$ in comparison to group 2 (94.4 \pm 3.2$)$. This difference was also not statistically significant $(\mathrm{p}=0.361)$. But excellent functional outcome was more in group $1(80.0 \%)$ in comparison to group $2(73.3 \%)$ whereas no poor or fair outcome was reported in group 1 but fair outcome was reported in $6.7 \%$ of patients in group 2. Overall complication rate was $6.67 \%$ with no significant intergroup difference. Conclusions: Quadrupled semitendinosus-gracilis auto graft has yielded more excellent results than tripled semitendinosus graft. But as this difference was not significant, it can be said that, both the procedure can be performed for arthroscopic reconstruction of ACL.
\end{abstract}

Keywords:- Arthroscopic reconstruction, ACL, quadrupled semitendinosus-gracilis, tripled semitendinosus, graft.

\section{INTRODUCTION}

The incidence of ACL ruptures is estimated to range from 30 to 78 per 100,000 person-years.[1] The most common mechanism of ACL tear or sprain is that of a sudden pivoting or cutting maneuver during sporting activity, which is commonly seen in football, basketball and soccer. The ligament can also tear due to work injuries or automobile accidents. Female 
Annals of International Medical and Dental Research E-ISSN: 2395-2822 | P-ISSN: 2395-2814

Vol-8, Issue-2 | March-April 2022

DOI: 10.53339/aimdr.2022.8.2.20

Page no- 145-156 | Section- Research Article (Orthopedics)

gender, younger age and contact sports are associated with a higher incidence of ACL injuries.[2] ACL tear often results in joint effusion, affects knee stability resulting in episodes of giving way, reduced functional performance, and may lead to the loss of an entire season or more of sports participation among young athletes.[3] As a result of instability of knee, there is also decreased ability to perform strenuous activities in daily life and sports activities of young age group, increased risk of meniscal injuries, and early degeneration of the injured knee.[4] Arthroscopic assisted Reconstruction of torn ACL with an intra-articular graft has become the most common method in ACL surgery. The various choices of auto grafts for ACL reconstruction includes bone patellar tendon bone (BPTB), quadrupled semitendinosusgracilis (STG) or tripled semitendinosus (ST) and quadriceps tendon. During the last decade, hamstring tendon auto grafts in the form of tripled semitendinosus (ST) or quadrupled semitendinosus and gracilis (STG) has become an increasingly used alternative for ACL reconstruction because of relatively low donor site morbidity and high level of patient acceptance.[5] Arthroscopic ACL reconstruction using quadrupled hamstring tendon graft with bio absorbable interference screw fixation showed $81 \%$ excellent or good outcome and concluded that use of hamstring tendon autograft for ACL reconstruction appears to be safe and effective.[6] Arthroscopic ACL reconstruction using tripled semitendinosus tendon graft showed $86 \%$ excellent or good outcome and concluded that for arthroscopic ACL reconstruction, [ $\underline{\text { ] }}$ choice of semitendinosus tendon alone preserving gracilis, comparable outcome as with STG graft, can be achieved, minimizing the hamstring strength deficit. Moreover gracilis being reserved for future use in revision ACL reconstruction and/or in other reconstructive surgery.

Considering these facts, current study was designed to compare the outcome of arthroscopic ACL reconstruction by quadrupled semitendinosus-gracilis and tripled semitendinosus auto graft, is time worthy.

\section{MATERIAL AND METHODS}

Data were prospectively collected at Level-3 trauma centre: National Institute of Traumatology \& Orthopaedic (NITOR), Dhaka from May 2017 to Aug 2019. This study was approved by the respective Institutional Review Boards (NITOR/ACADEMY/PHASEB/MARCH-15/5875) and performed under waiver of consent. Criteria for inclusion in this study were patients 18 to 49 years old who presented to the Outdoor Patient Department and diagnosed as a case Isolated ACL tear. Exclusion criteria were any patient $<18$ and $>$ 49 years, presence of fracture around the knee, multiple ligament injuries, associated meniscus injury, previous open surgery for knee injuries, time interval since injury less than 6 weeks, loss of knee motion and knee osteoarthritis. Clinical data collected include: age, gender, occupation, educational qualification, affected knee, causes of injury, preoperative lachman test, preoperative anterior drawer test (ADT), preoperative lysholm knee score, reconstruction technique, postoperative lachman test, postoperative anterior drawer test (ADT), postoperative lysholm knee score and complication. 
Annals of International Medical and Dental Research

E-ISSN: 2395-2822 | P-ISSN: 2395-2814

Vol-8, Issue-2 | March-April 2022

DOI: 10.53339/aimdr.2022.8.2.20

Page no- 145-156 | Section- Research Article (Orthopedics)

The study population was patients presented with unilateral knee complaints and diagnosis done by complete history, clinical examination and MRI evaluation. Total 60 patients were included in the study following the inclusion and exclusion criteria. 30 patients were included in group I and 30 were in group II. The purpose and procedure of the study were discussed with the patients. The patients were then admitted after counseling for surgery. Pre-operative data were collected including Lachman test, ADT and lysholm knee score in all the patients. Then the patients were investigated for anesthetic check-up and prepared for the operation. An informed written consent was taken from all patients. After proper pre-operative check-up and discussing the technique with the surgical team, operation was performed methodically. Each patient followed up for 24 weeks postoperatvely. Post-operative data were collected including lachman test, ADT, lysholm knee score in all the patients and recorded for evaluation of final outcome. The data were collected in a structured data collection form with a pre-tested structured questionnaire containing all the variables of interest by interview, observation, clinical examinations and imaging findings. All the data were edited for calculation and assessment. The data were tabulated and quantitative parameters of patient were summarized in terms of mean with standard deviation, to understand the variations present in the data. Percentage expression for positivity of scoring estimated along with $95 \%$ confidence interval. The significance of the results as determined in $95.0 \%$ confidence interval and a value of $p$ $<0.05$ considered to be statistically significant.
For calculations Microsoft excel software was used.

\section{RESULTS}

A total of 60 patients treated with ACL reconstruction surgery were enrolled in this study. In group 1 quadrupled semitendinosusgracilis graft and in group 2 tripled semitendinosus graft was used for the reconstruction. All these patients were available for follow-up up to 24 weeks. The mean age of the respondents was $26.4 \pm 6.8$ years. The age of most of the patients lied between 16 and 25 years (55.0\%) and age of a small number of patients were in group 36-45 years $(10.0 \%)$ [Table 1], majority of the respondents were males (98.3\%) [Table 2]. Most of the respondents were educated up to secondary level $(36.7 \%)$ followed by graduate $(30.0 \%)$ and higher secondary level (28.3\%) [Table 3] and more than half of them are service holder [Table 4]. Right sided knee injury was more common $(58.3 \%)$ than the left knee [Table 5]. Sports were the commonest causes of injury $(75.0 \%)$ of both groups of the patients followed by road traffic accident (18.3\%) [Table 6], amongst the sports related incident playing football was the most common cause of injury $(93.3 \%)$ followed by playing cricket $(6.7 \%)$ [Table 7].

Preoperative Lachman test [Table 8] and ADT [Table 9] were positive in all cases. Preoperative Lysholm knee score was almost similar in group $1(63.4 \pm 2.1)$ and in group 2 (63.1 \pm 2.5$)$ [Figure 1] and poor category patient was more in group $2(73.3 \%)$ in comparison to group $1(70.0 \%)$ but fair category patient was reported in $30.0 \%$ of patients in group 1 and $26.7 \%$ in group 2 whereas no good and 
Annals of International Medical and Dental Research E-ISSN: 2395-2822 | P-ISSN: 2395-2814

Vol-8, Issue-2 | March-April 2022

DOI: 10.53339/aimdr.2022.8.2.20

Page no- 145-156 | Section- Research Article (Orthopedics)

excellent category patient was reported in both the groups [Table 10]. Mean post-operative hospital stay was little bit higher in Group-1 (3.5 \pm 0.8 days) in comparison to Group-2 (3.3 \pm 0.8$)$ [Table 11]. Postoperatively at 24th week Lachman test [Table 12] and ADT [Table 13] was negative in all patients of both groups of the patients. Lysholm knee score at 24th week was slightly higher in group 1 (95.0 2.0$)$ in comparison to group $2(94.4 \pm 3.2)$ but there was no statistically significant difference is noted between these groups $(p=0.361)$
[Figure 2], excellent functional outcome was more in group $1(80.0 \%)$ in comparison to group $2(73.4 \%)$ whereas no poor or fair outcome was reported in group 1 but fair outcome was reported in $1.7 \%$ of patients in group 2. However, this association was not statistically significant $(p=0.650)$ [Table 14]. The postoperative complications at 24th week, includes pain was more in group $2(6.7 \%)$ in comparison to group $1(3.3 \%)$, infection was present in group 2(3.3\%) whereas no infection was reported in group 1 [Table 15].

Table 1: Age distribution of the patients

\begin{tabular}{|l|l|l|l|c|}
\hline Age (years) & Group A (n=30) & Group B (n=30) & Total (n=60) & P value \\
\cline { 1 - 3 } $16-25$ & $17(56.7)$ & $16(53.3)$ & $33(55.0)$ & \multirow{2}{*}{} \\
\cline { 1 - 3 } & $10(33.3)$ & $11(36.7)$ & $21(35.0)$ & \\
\hline $36-45$ & $3(10.0)$ & $3(10.0)$ & $6(10.0)$ & $0.588 \mathrm{~b}$ \\
\hline Mean \pm SD & $26.8 \pm 7.4$ & $25.9 \pm 6.3$ & $26.4 \pm 6.8$ & \\
\hline Total & $30(100.0)$ & $30(100.0)$ & $60(100.0)$ & \\
\hline
\end{tabular}

aFisher's Exact Test; bunpaired t-test

Table 2: Gender of the patients

\begin{tabular}{|l|l|l|l|c|}
\hline Sex & Group A (n=30) & Group B (n=30) & Total (n=60) & P value \\
\cline { 1 - 4 } Male & $29(96.7)$ & $30(100.0)$ & $59(98.3)$ & \multirow{2}{*}{$1.000 \mathrm{a}$} \\
\cline { 1 - 4 } Temale & $1(3.3)$ & $0(0.0)$ & $1(1.7)$ & \\
\hline
\end{tabular}

aFisher's Exact Test

Table 3: Educational qualification of the patients

\begin{tabular}{|l|l|l|l|l|}
\hline Education Qualification & Group A (n=30) & Group B (n=30) & Total $(\mathbf{n}=\mathbf{6 0})$ & P value \\
\hline Primary & $3(10.0)$ & $0(0.0)$ & $3(5.0)$ & $0.248 \mathrm{a}$ \\
\hline Secondary & $9(30.0)$ & $13(43.3)$ & $22(36.7)$ & \\
\hline Higher secondary & $10(33.3)$ & $7(23.3)$ & $17(28.3)$ \\
\hline Graduate & $8(26.7)$ & $10(33.3)$ & $18(30.0)$ & \\
\hline Total & $30(100.0)$ & $30(100.0)$ & $60(100.0)$ & \\
\hline
\end{tabular}

aFisher's Exact Test 
Annals of International Medical and Dental Research E-ISSN: 2395-2822 | P-ISSN: 2395-2814

Vol-8, Issue-2 | March-April 2022

DOI: 10.53339/aimdr.2022.8.2.20

Page no- 145-156 | Section- Research Article (Orthopedics)

The mean age of the respondents was $26.4 \pm 6.8$ years. The age of most of the patients lied between 16 and 25 years (55.0\%) and age of a small number of patients were in group 36-45 years (10.0\%). Statistically no significant difference is noted between these two groups [Table 1].

[Table 2] shows that majority of the respondents were males (98.3\%). The male-female ratio was 59:1. The difference in male and female between two groups was not statistically significant $(\mathrm{p}=1.000)$

[Table 3] illustrates that majority of the respondents were educated up to secondary level (36.7\%) followed by graduate $(30.0 \%)$ and higher secondary level $(28.3 \%)$. The distribution of educational qualifications of both groups was almost similar.

Table 4: Occupation of the patients

\begin{tabular}{|c|c|c|c|c|}
\hline Occupation & Group A $(n=30)$ & Group B $(n=30)$ & Total $(n=60)$ & P value \\
\hline Student & $12(40.0)$ & $12(40.0)$ & $24(40.0)$ & \multirow{4}{*}{$0.563 a$} \\
\hline Service holder & $14(46.7)$ & 17 (56.7) & 31 (51.7) & \\
\hline Businessman & $2(6.7)$ & $1(3.3)$ & $3(5.0)$ & \\
\hline Ohers & $2(6.7)$ & $0(0.0)$ & $2(3.3)$ & \\
\hline Total & $30(100.0)$ & $30(100.0)$ & $60(100.0)$ & \\
\hline
\end{tabular}

aFisher's Exact Test

[Table 4] depicts that more than half of the respondents were service holders (51.7\%) followed by students $(40.0 \%)$. The distribution of occupation of both groups was more or less similar.

Table 5: Affected knees of the patients

\begin{tabular}{|l|l|l|l|c|}
\hline Affected knee & Group A (n=30) & Group B (n=30) & Total (n=60) & P value \\
\hline Right & $20(66.7)$ & $15(50.0)$ & $35(58.3)$ & $0.190 a$ \\
\hline Left & $10(33.3)$ & $15(50.0)$ & $25(41.7)$ & \\
\hline Total & $30(100.0)$ & $30(100.0)$ & $60(100.0)$ & \\
\hline
\end{tabular}

aChi square test

As shown in [Table 5], the right sided knee injury was more common (58.3\%) than the left knee. In group 1, right knee injury was two times higher than left side; whereas in group 2, both knee injuries were equal.

Table 6: Causes of the injury of the patients

\begin{tabular}{|l|l|l|l|c|}
\hline Causes of the injury & Group A (n=30) & Group B (n=30) & Total (n=60) & P value \\
\hline Sports & $24(80.0)$ & $21(70.0)$ & $45(75.0)$ & $0.190 \mathrm{a}$ \\
\cline { 1 - 4 } Road Traffic Accident & $4(13.3)$ & $7(23.3)$ & $11(18.3)$ & \\
\hline Other & $2(6.7)$ & $2(6.7)$ & $4(6.7)$ & \\
\hline Total & $30(100.0)$ & $30(100.0)$ & $60(100.0)$ & \\
\hline
\end{tabular}

aFisher's Exact Test 
Annals of International Medical and Dental Research

E-ISSN: 2395-2822 | P-ISSN: 2395-2814

Vol-8, Issue-2 | March-April 2022

DOI: $10.53339 /$ aimdr.2022.8.2.20

Page no- 145-156 | Section- Research Article (Orthopedics)

As described in [Table 6], sports were the commonest causes of injury $(75.0 \%)$ of both groups of the patients followed by road traffic accident $(18.3 \%)$.

Table 7: Sports related injuries of the respondents

\begin{tabular}{|l|c|c|l|}
\hline Mechanism of the injury & Group A $\mathbf{n = 3 0 ( \% )}$ & Group B $\mathbf{n = 3 0 ~ ( \% ) ~}$ & Total (n=60) \\
\hline Football & $23(51.1)$ & $19(42.2)$ & $42(93.3)$ \\
\hline Cricket & $1(2.2)$ & $2(4.5)$ & $3(6.7)$ \\
\hline Others & $0(0.0)$ & $0(0.0)$ & $0(0.0)$ \\
\hline
\end{tabular}

Table 8: Preoperative lachman test

\begin{tabular}{|l|l|l|l|l|}
\hline Lachman test & Group A (n=30) & Group B $(\mathbf{n}=\mathbf{3 0})$ & Total $(\mathbf{n}=\mathbf{6 0})$ & P value \\
\hline Positive & $30(100.0)$ & $30(100.0)$ & $30(100.0)$ & \\
\cline { 1 - 4 } Negative & $0(0.0)$ & $0(0.0)$ & $0(0.0)$ & \\
\hline Total & $30(100.0)$ & $30(100.0)$ & $60(100.0)$ & \\
\hline
\end{tabular}

Table 9: Preoperative anterior drawer test

\begin{tabular}{|l|l|l|l|c|}
\hline Anterior drawer test & Group A (n=30) & Group B (n=30) & Total (n=60) & P value \\
\hline Positive & $30(100.0)$ & $30(100.0)$ & $30(100.0)$ & - \\
\hline Negative & $0(0.0)$ & $0(0.0)$ & $0(0.0)$ & \\
\hline Total & $30(100.0)$ & $30(100.0)$ & $60(100.0)$ & \\
\hline
\end{tabular}

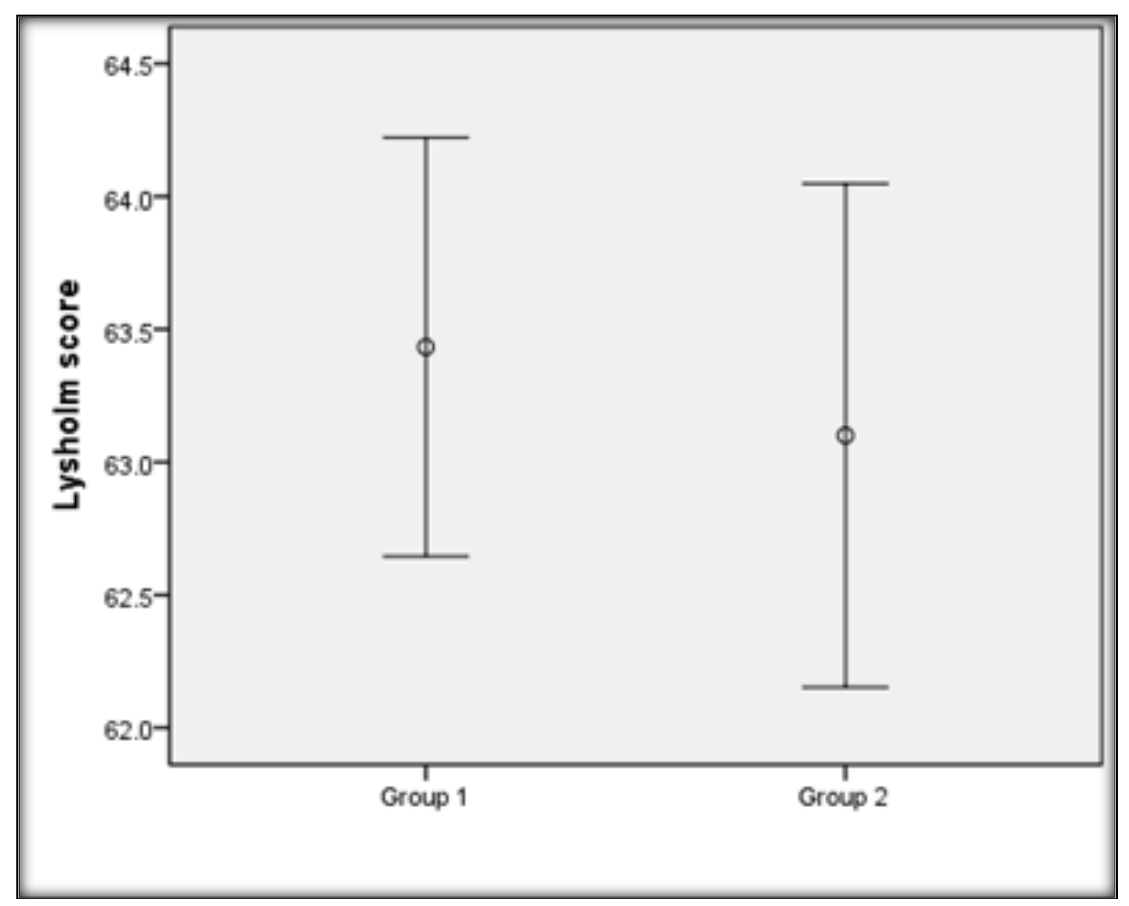

Figure 1: Comparison of preoperative Lysholm score 
Annals of International Medical and Dental Research E-ISSN: 2395-2822 | P-ISSN: 2395-2814

Vol-8, Issue-2 | March-April 2022

DOI: 10.53339/aimdr.2022.8.2.20

Page no- 145-156 | Section- Research Article (Orthopedics)

[Table 7] describes amongst the 45 sports related incident playing football was the most common cause of injury (93.3\%) followed by playing cricket $(6.7 \%)$.

[Table 8] shows that lachman test was positive in all patients of both groups. There was no difference in preoperative lachman test between two groups.

[Table 9] shows that anterior drawer test was positive in all patients of both groups. There was no difference in preoperative anterior drawer test between two groups.

As shown in [Figure 1], preoperative Lysholm knee score was almost similar in group 1 (63.4 \pm 2.1$)$ and in group $2(63.1 \pm 2.5)$. This difference was not statistically significant $(p=0.582)$.

Table 10: Preoperative Lysholm knee score

\begin{tabular}{|l|l|l|l|l|}
\hline Category & Group A (n=30) & Group B (n=30) & Total $(\mathbf{n}=60)$ & P value \\
\hline Poor & $21(70.0)$ & $22(73.3)$ & $43(71.7)$ & \multirow{2}{*}{$0.082 \mathrm{a}$} \\
\hline Fair & $9(30.0)$ & $8(26.7)$ & $17(28.3)$ & \\
\hline Good & $0(0.0)$ & $0(0.0)$ & $0(0.0)$ & \\
\hline Excellent & $0(0.0)$ & $0(0.0)$ & $0(0.0)$ & $6(100.0)$ \\
\hline Total & $30(100.0)$ & $30(100.0)$ & $60)$ & \\
\hline
\end{tabular}

aChi square test

[Table 10] shows that poor category patient was more in group 2 (73.3\%) in comparison to group 1 $(70.0 \%)$ but fair category patient was reported in $30.0 \%$ of patients in group 1 and $26.7 \%$ in group 2 whereas no good and excellent category patient was reported in both the groups. However, this association was not statistically significant $(\mathrm{p}=0.082)$.

Table 11: Duration of postoperative hospital stay

\begin{tabular}{|l|l|l|l|c|}
\hline Group & Number & Mean (day) & SD & P value \\
\cline { 1 - 3 } Group 1 & 30 & 3.5 & 0.86 & \\
\cline { 1 - 4 } Group & 30 & 3.2 & 0.85 & \\
\hline Total & 60 & 3.3 & 0.86 & \\
\hline
\end{tabular}

aUnpaired $t$ test

[Table 11] shows that the mean post-operative hospital stay was little bit higher in Group-1 (3.5 \pm 0.8 days) in comparison to Group-2 (3.3 \pm 0.8$)$. The difference in post-operative hospital stay between two groups were not statistically significant $(\mathrm{p}=0.182)$.

Table 12: Lachman test at $24^{\text {th }}$ week

\begin{tabular}{|l|l|l|l|l|}
\hline Lachman test & Group A (n=30) & Group B (n=30) & Total $(\mathbf{n}=\mathbf{6 0 )}$ & P value \\
\hline Positive & $0(0.0)$ & $0(0.0)$ & $0(0.0)$ & \\
\hline Negative & $30(100.0)$ & $30(100.0)$ & $30(100.0)$ & \\
\hline Total & $30(100.0)$ & $30(100.0)$ & $60(100.0)$ & \\
\hline
\end{tabular}

Copyright: (The author(s), published in Annals of International Medical and Dental Research, Vol-8, Issue-2. This is an open access article under the Attribution-Non Commercial 2.0 Generic (CC BY-NC 2.0) license. (https://creativecommons.org/licenses/by-nc/2.0/) 
Annals of International Medical and Dental Research

E-ISSN: 2395-2822 | P-ISSN: 2395-2814

Vol-8, Issue-2 | March-April 2022

DOI: 10.53339/aimdr.2022.8.2.20

Page no- 145-156 | Section- Research Article (Orthopedics)

[Table 12] shows that Lachman test was negative in all patients of both groups of the patients. There was no difference in post-operative Lachman test between two groups.

Table 13: Anterior drawer test at $24^{\text {th }}$ week

\begin{tabular}{|l|l|l|l|l|}
\hline Anterior drawer test & Group A (n=30) & Group B (n=30) & Total (n=60) & P value \\
\hline Positive & $0(0.0)$ & $0(0.0)$ & $0(0.0)$ & - \\
\hline Negative & $30(100.0)$ & $30(100.0)$ & $30(100.0)$ \\
\hline Total & $30(100.0)$ & $30(100.0)$ & $60(100.0)$ & \\
\hline
\end{tabular}

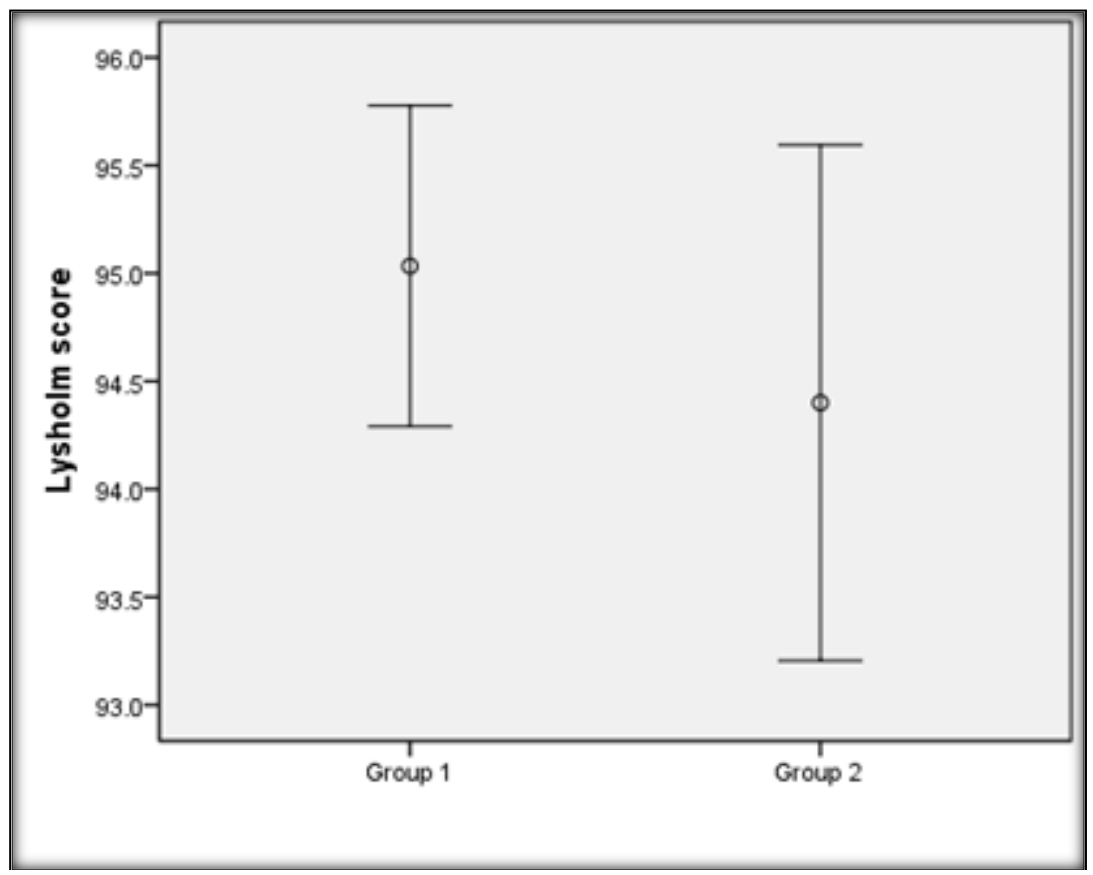

Figure 2: Comparison of post-operative Lysholm knee score at 24th week

Table 14: Lysholm knee score at 24th week

\begin{tabular}{|l|l|l|l|c|}
\hline Category & Group A (n=30) & Group B (n=30) & Total $(\mathbf{n}=60)$ & P value \\
\hline Poor & $0(0.0)$ & $0(0.0)$ & $0(0.0)$ & $0.650 a$ \\
\hline Fair & $0(0.0)$ & $1(3.3)$ & $1(1.7)$ & \\
\hline Good & $6(20.0)$ & $7(23.3)$ & $13(21.7)$ & \\
\hline Excellent & $24(80.0)$ & $22(73.4)$ & $46(76.6)$ & \\
\hline Total & $30(100.0)$ & $30(100.0)$ & $60(100.0)$ & \\
\hline
\end{tabular}

aFisher's Exact Test

[Table 13] shows that anterior drawer test was negative in all patients of both groups of the patients. There was no difference in post-operative anterior drawer test between two groups. 
Annals of International Medical and Dental Research

E-ISSN: 2395-2822 | P-ISSN: 2395-2814

Vol-8, Issue-2 | March-April 2022

DOI: $10.53339 /$ aimdr.2022.8.2.20

Page no- 145-156 | Section- Research Article (Orthopedics)

As shown in [Figure 2], Lysholm knee score at 24th week was slightly higher in group 1 (95.0 22.0$)$ in comparison to group $2(94.4 \pm 3.2)$. Unpaired $t$ test was done, and this difference was not statistically significant $(\mathrm{p}=0.361)$.

[Table 14] shows that excellent functional outcome was more in group $1(80.0 \%)$ in comparison to group $2(73.4 \%)$ whereas no poor or fair outcome was reported in group 1 but fair outcome was reported in $1.7 \%$ of patients in group 2 . However, this association was not statistically significant $(p=0.650)$.

Table 15: Postoperative complications at $24^{\text {th }}$ week

\begin{tabular}{|l|l|l|l|}
\hline Complications & Group A n=30 (\%) & Group B n=30 (\%) & Total (n=60) \\
\hline Pain & $1(3.3)$ & $2(6.7)$ & $3(5.0)$ \\
\hline Infection & $0(0.0)$ & $1(3.3)$ & $1(1.7)$ \\
\hline Others & $0(0.0)$ & $0(0.0)$ & $0(0.0)$ \\
\hline Total & $1(3.3)$ & $3(10.0)$ & $4(6.7)$ \\
\hline
\end{tabular}

[Table 15] illustrates the postoperative complications at 24th week, includes pain was more in group $2(6.7 \%)$ in comparison to group 1 (3.3\%), infection was present in group $2(3.3 \%)$ whereas no infection was reported in group 1.

\section{DISCUSSION}

Anterior cruciate ligament tear often leads to instability of the knee especially during exercise or heavy work, and in such cases usually requires surgical treatment. Reconstruction of the anterior cruciate ligament (ACL) is among the most frequently performed procedure in knee surgery now days. The aim of this study is to assess the comparative outcome of the arthroscopic ACL reconstruction by quadrupled semitendinosusgracilis and tripled semitendinosus auto graft.

In this study the mean age of the respondents was $26.4 \pm 6.8$ years. The age of most of the patients lied between 16 and 25 years $(55.0 \%)$ and age of a small number of patients were in group 36-45 years (10.0\%). Majority of the respondents were males $(98.3 \%)$. The malefemale ratio was 59:1. Similarly another study, the mean age in their series was 31.8 years with a range from 19-50 years. The male to female ratio was 5:1.[] Majority of the respondents were educated up to secondary level (36.7\%) followed by graduate $(30.0 \%)$ and higher secondary level $(28.3 \%)$. The distribution of educational qualifications of both groups was almost similar. More than half of the respondents were service holders (51.7\%) followed by students $(40.0 \%)$. Another study conducted in Bangladesh found in terms of occupation $42.8 \%, 30.2 \%, 19.0 \%, 4.8 \%$ and $3.2 \%$ were student, service holder, businessmen, house wife and armed forces personnel respectively. [9] The right sided knee injury was more common $(58.3 \%)$ than the left knee injury. In group 1, right knee injury was two times higher than left side; whereas in group 2, both knee injuries were equal. But dissimilarly in another study, of the 72 knees studied, 41 (56.9\%) were left knees and 31 (43.1\%) were 
Annals of International Medical and Dental Research E-ISSN: 2395-2822 | P-ISSN: 2395-2814

Vol-8, Issue-2 | March-April 2022

DOI: 10.53339/aimdr.2022.8.2.20

Page no- 145-156 | Section- Research Article (Orthopedics)

right knees.[10] Sports were the commonest causes of injury $(75.0 \%)$ of both groups of the patients followed by road traffic accident $(18.3 \%)$. Playing football was the most common cause of the sports related injury (93.3\%) followed by cricket $(6.7 \%)$. Bhat et al, in their study observed sports injury accounted for $46.7 \%$ of the cases. [8] Preoperative lachman test was positive in all patients of both groups. There was no significant difference in preoperative Lachman test between two groups. Thapa et al. found similar high positive Lachman test result in ACL injury of majority $(91.43 \%)$ of the respondent. ${ }^{[11]}$

Preoperative anterior drawer test was positive in all patients of both groups. There was no significant difference in preoperative anterior drawer test between two groups. Preoperative Lysholm score was almost similar in group 1 $(63.4 \pm 2.1)$ and in group $2(63.1 \pm 2.5)$. This difference was not statistically significant $(p=0.582)$. Poor category patients was more in group $2(73.3 \%)$ then group $1(70.0 \%)$ whereas no good and excellent category patient was reported in both the groups but fair category was reported in $30 \%$ of patients in group 1 and $26.7 \%$ in group 2. The mean post-operative hospital stay was little bit higher in Group-1 (3.5 \pm 0.8 days) in comparison to Group-2 $(3.3 \pm 0.8)$. The difference in post-operative hospital stay between two groups was not statistically significant $(p=0.182)$. Whereas Lopes et al.112] evaluated the epidemiology of ACLR in the Brazilian public health system and reported an average length of stay of 1.8 days in 2014. Islam et al.[7] showed in their study that mean post-operative hospital stay was 6.14 days. Postoperative Lachman test and anterior drawer test at 24th week was negative in all patients of both groups. Lysholm score at 24th week was slightly higher in group 1 $(95.0 \pm 2.0)$ in comparison to group $2(94.4 \pm 3.2)$. Unpaired $t$ test was done, and this difference was not statistically significant $(p=0.361)$. Similar improvement were found in a previous study by using Quadrupled semitendinosus graft that Lysholm scoring significantly improved from mean preoperative scoring $58.76 \pm 15.29$ to a mean postoperative score of 91.16 \pm 3.87 (Chodavarapu et al., 2017).[13] Islam et al.77 (2017) found in their study by using Tripled semitendinosus tendon graft Lysholm knee score significantly improved from mean preoperative scoring $52.64 \pm 4.256$ to a mean postoperative score of 92 .

In this study on interpretation of Lysholm knee scoring showed excellent functional outcome was more in group $1(80.0 \%)$ in comparison to group $2(73.3 \%)$ whereas no poor outcome was reported in group 1 and group 2 but fair outcome was reported in $3.3 \%$ of patients in group 2. However, this association was not statistically significant $(\mathrm{p}=0.660)$. Chodavarapu et al. (2017) observed anterior cruciate ligament reconstruction surgery with quadrupled hamstring grafts, 13$]$ provides $72 \%$ excellent outcome to ACL injuries when the surgery is timed well, with sufficient graft thickness and good rehabilitation. Islam et al. (2017) found in their study by using Tripled semitendinosus tendon graft, provides $86 \%$ Satisfactory (excellent and good) outcome.[7] Arthroscopic ACLR using QHT auto graft and an accelerated post-operative rehabilitation program like the SERP has showed significant improvements in functional scores and helped the patient achieve an early pre-injury status. The two year follow-up results of ACLR with 
Annals of International Medical and Dental Research

E-ISSN: 2395-2822 | P-ISSN: 2395-2814

Vol-8, Issue-2 | March-April 2022

DOI: 10.53339/aimdr.2022.8.2.20

Page no- 145-156 | Section- Research Article (Orthopedics)

QHT graft are satisfactory (Shishir Murugharaj Suranigi, 2016).[14] In this study the postoperative complications at 24th weeks was pain $(5 \%)$ and infection $(1.7 \%)$. Pain was more in group $2(6.7 \%)$ in comparison to group 1 $(3.3 \%)$, infection was present in group $2(3.3 \%)$ whereas no infection was reported in group 1. Positive correlation observed in the study conducted by Eckmorde et al. observed shortterm complications following ACL reconstruction include infection and deficits to knee motion and strength,[15] whereas longterm complications include secondary ACL injury to either the involved or contralateral knee or lack of ability to return to high-level sports following this procedure.[15]

\section{CONCLUSIONS}

Quadrupled semitendinosus-gracilis auto graft has yielded more excellent results than tripled semitendinosus graft. But as this difference was not significant, it can be said that, both the

\section{REFERENCES}

1. Gans I, Retzky JS, Jones LC, Tanaka MJ. Epidemiology of Recurrent Anterior Cruciate Ligament Injuries in National Collegiate Athletic Association Sports: The Injury Surveillance Program, 2004-2014. Orthop J Sports Med. 2018;6(6):2325967118777823. $10.1177 / 2325967118777823$.

2. Prodromos CC, Han Y, Rogowski J, Joyce B, Shi K. A meta-analysis of the incidence of anterior cruciate ligament tears as a function of gender, sport, and a knee injury-reduction regimen. Arthroscopy. 2007;23(12):1320-1325.e6. doi: 10.1016/j.arthro.2007.07.003.

3. Kiapour AM, Murray MM. Basic science of anterior cruciate ligament injury and repair. Bone Joint Res. 2014;3(2):20-31. doi: 10.1302/2046-3758.32.2000241. procedure can be performed for arthroscopic reconstruction of ACL. Tthere were some limitation of the study; small sample size, short follow up period and operating surgeons were not same in all cases, which renders the operator dependent variation to some extent. Large scale studies with longer period follow up should be done for evaluation of long term outcome and the result of this study can be utilized for future larger study.

\section{Acknowledgment}

The authors graciously acknowledge the Arthroscopy unit of National institute of Traumatology \& Orthopedic Rehabilitation (NITOR), all the health professionals and staffs of NITOR who helped to collect these data. The authors also thank hospital professional research assistants for facilitating combination of our data.

4. Levy BA, Dajani KA, Morgan JA, Shah JP, Dahm DL, Stuart MJ. Repair versus reconstruction of the fibular collateral ligament and posterolateral corner in the multiligament-injured knee. Am J Sports Med. 2010;38(4):804-9. doi: 10.1177/0363546509352459.

5. Ejerhed L, Kartus J, Sernert N, Köhler K, Karlsson J. Patellar tendon or semitendinosus tendon autografts for anterior cruciate ligament reconstruction? A prospective randomized study with a two-year follow-up. Am J Sports Med. 2003;31(1):19-25. doi: 10.1177/03635465030310011401.

6. Charlton WP, Randolph DA Jr, Lemos S, Shields CL Jr. Clinical outcome of anterior cruciate ligament reconstruction with quadrupled hamstring tendon graft and bioabsorbable interference screw fixation. Am J Sports Med. 2003;31(4):518-21. doi: 10.1177/03635465030310040701.

7. Islam MZ, Rahman M, Ali ME, Alam MK, Ahmed W, Alam MT, Saha MK. Arthroscopic Anterior 
Annals of International Medical and Dental Research

E-ISSN: 2395-2822 | P-ISSN: 2395-2814

Vol-8, Issue-2 | March-April 2022

DOI: 10.53339/aimdr.2022.8.2.20

Page no- 145-156 | Section- Research Article (Orthopedics)

Cruciate Ligament Reconstruction with Triplet Autograft of Semitendinosus Tendon. Mymensingh Med J. 2017;26(3):545-550.

8. Bhat MS. Short term results of anterior cruciate ligament reconstruction using four strand hamstring tendon autograft with endobutton fixation. J Dent Med Sci. 2013;11:67-72.

9. Muktadir KM, Haque MM, Sultana S, Usmani N, Sakib MN, Zannath MM. Nutritional Status and Causes of Anterior Cruciate Ligament Injury in Relation with Exercise Habit Among Patients of a Tertiary Care Hospital. Chattagram Maa-O-Shishu Hosp Med College j. 2014;13:58-61.

10. Sgaglione NA, Warren RF, Wickiewicz TL, Gold DA, Panariello RA. Primary repair with semitendinosus tendon augmentation of acute anterior cruciate ligament injuries. Am J Sports Med. 1990;18(1):64-73. doi: $10.1177 / 036354659001800111$.

11. Jarbo KA, Hartigan DE, Scott KL, Patel KA, Chhabra A. Accuracy of the Lever Sign Test in the Diagnosis of Anterior Cruciate Ligament Injuries. Orthop J Sports Med. 2017;5(10):2325967117729809. doi:10.1177/2325967117729809
12. Lopes TJA, Simic M, Pappas E. Epidemiology of anterior cruciate ligament reconstruction in Brazil's public health system. Revista Brasileira de Medicina do Esporte. 2016;22:297-301.

13. Chodavarapu LM, Asif Hussain KS, Kumar KK, Patnala C, Yadoji H. Analysis of functional outcome of anterior cruciate ligament reconstruction using quadruple hamstring graft. Int $J$ Res Orthop. 2017;3:877.

14. Suranigi SM, Kanagasabai R, Najimudeen S, Gnanadoss JJ. Functional outcome of anterior cruciate ligament reconstruction with quadruple hamstring tendon graft using EndoButton and bioabsorbable interference screw: minimum 2-year follow-up. Int J Res Orthop. 2016;2:377.

15. Eckenrode BJ, Carey JL, Sennett BJ, Zgonis MH. Prevention and Management of Post-operative Complications Following ACL Reconstruction. Curr Rev Musculoskelet Med. 2017;10(3):315-321. doi: 10.1007/s12178-017-9427-2.

Source of Support: Nil, Conflict of Interest: None declared 